\title{
Globe
}

Revue internationale d'études québécoises

\section{Louis Rousseau et Frank W. Remiggi : Atlas historique des pratiques religieuses. Le sud-ouest du Québec au XIX $X^{e}$ siècle. Ottawa, Presses de l’Université d'Ottawa, 1998}

\section{Éric Bédard}

Volume 4, numéro 1, 2001

URI : https://id.erudit.org/iderudit/1000610ar

DOI : https://doi.org/10.7202/1000610ar

Aller au sommaire du numéro

Éditeur(s)

Globe, Revue internationale d'études québécoises

ISSN

1481-5869 (imprimé)

1923-8231 (numérique)

Découvrir la revue

Citer ce compte rendu

Bédard, É. (2001). Compte rendu de [Louis Rousseau et Frank W. Remiggi :

Atlas historique des pratiques religieuses. Le sud-ouest du Québec au XIX siècle. Ottawa, Presses de l’Université d'Ottawa, 1998]. Globe, 4(1), 157-160.

https://doi.org/10.7202/1000610ar d'utilisation que vous pouvez consulter en ligne.

https://apropos.erudit.org/fr/usagers/politique-dutilisation/ 


\section{Louis Rousseau et Frank W. Remiggi}

Atlas bistorique des pratiques religieuses.

Le sud-ouest du Québec au XIX $X^{e}$ siècle.

Ottawa, Presses de l'Université d'Ottawa, 1998.

Les atlas constituent toujours des outils précieux pour les chercheurs. Ils font gagner du temps à celui ou à celle qui veut obtenir une information pointue. Tel est le cas de l'Atlas bistorique des pratiques religieuses publié aux Presses de l'Université d'Ottawa en 1998 sous la direction de Louis Rousseau et de Frank W. Remiggi, tous deux professeurs à l'Université du Québec à Montréal. Fruit d'un immense travail de recherche, cet atlas a mobilisé une importante équipe d'assistants tout au long de son élaboration, qui a débuté en 1983. L'objet de cet atlas est bien circonscrit à la fois dans l'espace et dans le temps. Les pratiques religieuses méticuleusement répertoriées sont celles du sud-ouest québécois au $\mathrm{XIX}^{e}$ siècle. On est en présence d'une recherche exhaustive qui fourmille de tableaux, de chiffres et de "planches "sur les multiples facettes de la pratique religieuse.

L'ouvrage est divisé en trois parties. La première s'intéresse au territoire et à sa population. Les auteurs étudient le "paysage sociodémographique " du sud-ouest québécois, analysent l'évolution de la "présence pastorale " et tentent notamment de décrire le phénomène des " missions populaires ". Dans la seconde partie, on passe en revue "l'économie religieuse et le patrimoine sacré . Tableaux à l'appui, on calcule les revenus du clergé et on vérifie dans le détail la gestion des fabriques et des institutions qui en dépendaient. La dernière partie - la plus riche à mes yeux - est consacrée aux "comportements religieux ". Toutes les étapes de la vie des fidèles sont passées au peigne fin. Les taux de "communiants" et de "non-pascalisants "sont évalués avec rigueur et finesse. Il en va de même de l'univers des dévotions et de la présence des associations paroissiales qui sont analysés avec la loupe de chercheurs désireux d'aller au bout de leur enquête.

Si Rousseau, Remiggi et leur équipe s'en étaient tenus à cet imposant répertoire de données, nous n'aurions qu'à nous incliner devant 
tant d'érudition. Car il faudra du temps et de la patience avant qu'un tel outil de recherche ne soit dépassé. Cette somme a les allures d'une œuvre définitive sur la question. Et il faut remercier ces chercheurs d'avoir avec autant de persistance fait reculer les frontières de la connaissance. Mais il y a plus qu'une brillante démonstration d'érudition dans cet atlas. Les auteurs y défendent une thèse et servent avec vigueur un parti pris historiographique.

Au cours des dernières décennies, deux visions se sont affrontées quant à la nature des pratiques religieuses des Canadiens français au $\mathrm{XIX}^{\mathrm{e}}$ siècle. La première vision, défendue notamment par l'historien René Hardy, considère que l'imprégnation croissante des pratiques catholiques dans la culture quotidienne des Canadiens français fut graduelle et résultait en bonne partie d'une "stratégie " de "contrôle social " mise en place par le clergé. L'autre vision, mise de l'avant par Louis Rousseau depuis longtemps, insiste sur le caractère brusque et populaire d'un "réveil religieux " qui serait apparu durant les années 1840. Dans un article publié en 1986 (dans Religion et culture au Québec. Figures contemporaines du sacré, sous la direction de Yves Desrosiers, Montréal, Fides, 1986), Rousseau insiste sur une "transformation importante des mentalités dans la masse "durant cette période. À ses yeux, la thèse du contrôle social était nettement insuffisante pour rendre compte de l'hégémonie de la religion catholique dans la culture canadiennefrançaise.

On le devine, c'est cette seconde thèse que défend l'atlas. Durant le premier tiers du xix ${ }^{e}$ siècle, expliquent Rousseau et Remiggi dans leur introduction, le Bas-Canada est soumis à un choc d'une très grande ampleur. La crise de l'économie rurale, les pressions démographiques, les tensions socio-ethniques et la crise politique qui toutes font rage durant les années 1830 représentent autant de "forces de distorsion " qui menacent la survie de la société canadienne-française. Face à une possible " désagrégation culturelle ", un processus de revitalisation s'amorce au début des années 1840. Au Canada français, cette revitalisation culturelle s'exprime à travers " un retour à l'héritage catholique, mais sous sa modalité nouvelle ultramontaine ". Ce réveil religieux n'est donc pas le simple fait d'un contrôle social plus serré du clergé. Car pour nos 
auteurs, "le système religieux, au sein de la culture, déborde l'organisation cléricale de toutes parts et ne peut se réduire à cette dernière . Dans l'esprit de Rousseau et de Remiggi, les pratiques religieuses sont un fait de culture qui mettent "en relations des représentations générales et particulières du monde ". Ce réveil religieux inaugure une nouvelle phase culturelle au Canada français qui va se déployer jusqu'à la fin des années 1860 ; après cette date, les pratiques religieuses vont faire partie du paysage culturel, elles vont se " routiniser *

Sans s'en tenir exclusivement à la thèse du " réveil ", l'atlas de Rousseau et de Remiggi fournit un grand nombre d'indicateurs qui rendent cette interprétation très convaincante. À partir de 1840 , les habits du patrimoine sacré tendent à se transformer. Sur les chemins, on aperçoit subitement un très grand nombre de croix. Il en est de même des églises, dont la conception est peu à peu confiée à des architectes professionnels. Ces derniers proposent aux clercs des édifices imposants qui témoignent de la grandeur de l'Église et de la place qu'elle en vient à occuper dans la vie quotidienne des gens. En plus des apparats propres à l'institution ecclésiastique, les comportements des fidèles fournissent des indices encore plus convaincants du réveil religieux. Durant la décennie 1840 , les vocations augmentent très rapidement, ainsi que les confréries de dévotion et les associations volontaires - celles qui prônent la tempérance par exemple. Les missions populaires de ForbinJanson et, plus tard, de Chiniquy attirent des dizaines de milliers de personnes. Le passage du premier aura un effet net sur laccroissement des pascalisants. Pour la paroisse de Notre-Dame-de-Montréal, le taux de pascalisants va passer de $38,6 \%$ en 1839 à $76,7 \%$ en 1843 . C'est tout dire !

On le voit, Rousseau et Remiggi ont voulu défendre leur parti pris historiographique en ayant recours à la méthode quantitative élaborée il y a près d'un demi-siècle par le sociologue français Gabriel LeBras. Il va sans dire que tant d'attitudes "observables" ne peuvent rendre compte de "l'organisation d'une disposition intérieure ". Les auteurs sont conscients de cette limite et c'est à dessein qu'ils ont privilégié une comptabilité scrupuleuse des comportements et des pratiques plutôt qu'une analyse qualitative de récits autobiographiques et autres 
témoignages personnels. La justification de cette option méthodologique est connue : les masses laissent peu d'écrits. La forme de l'atlas était donc toute désignée pour fournir aux chercheurs intéressés par ce débat les preuves définitives du réveil religieux dans le Canada français du xux siècle. Il reste maintenant à espérer que des chercheurs iront fouiller les biographies personnelles de ces fidèles d'un genre nouveau. Comment ce réveil a-t-il été vécu de l'intérieur par celles et ceux, nombreux, qui y ont cru? Pourquoi cet attrait soudain pour l'héritage catholique? Pour y voir plus clair, pour mieux comprendre ce qui a pu se passer, il nous faudra bien un jour suivre les traces de quelques-uns d'entre eux.

Éric Bédard Université McGill

\section{Garth Stevenson}

Community Besieged.

The Anglophone Minority

and the Politics of Quebec

Montréal, McGill-Queen's University Press, 1999.

La communauté anglophone du Québec existe depuis la Conquête. Son rôle était des plus importants sur le plan économique et social jusqu'à l'époque de la Révolution tranquille. Malgré une chute démographique qui a vu le départ d'un quart de million d'anglophones depuis les années 1960, la communauté anglophone jouit du rôle d'unique minorité officielle anglophone au pays (et sur le continent nordaméricain). Le livre de Garth Stevenson est une étude approfondie de l'histoire politique de cette communauté depuis la Confédération, la seule étude contemporaine remontant jusqu'aux origines de la présence anglophone au Québec, ce qui permet à l'auteur de mieux situer la rupture qui est survenue au cours des années 1960.

Le livre de Stevenson s'inspire de la thèse du politologue Arend Lijphart sur le consociationalisme démocratique. En peu de mots, 